\title{
Seasonal variation in semen quality of Dorper rams using different collection techniques
}

\author{
C.M. Malejane ${ }^{1}$, J.P.C. Greyling ${ }^{2 \#} \&$ M.B. Raito ${ }^{2}$ \\ ${ }^{1}$ Department of Animal Science and Production, Botswana College of Agriculture, Gaborone, Botswana \\ ${ }^{2}$ Department of Animal, Wildlife and Grassland Sciences, University of the Free State, Bloemfontein, South Africa
}

(Received 5 August 2013; Accepted 7 January 2014; First published online 8 February 2014)

Copyright resides with the authors in terms of the Creative Commons Attribution 2.5 South African Licence.
See: http://creativecommons.org/licenses/by/2.5/za
Condition of use: The user may copy, distribute, transmit and adapt the work, but must recognise the authors and the South African
Journal of Animal Science.

\begin{abstract}
The aim of the study was to evaluate the seasonal variation in semen quality of Dorper rams using different semen collection techniques. The study was carried out from January 2012 to January 2013. A general management programme for health control was followed, with water being provided ad libitum throughout the trial, and all rams being fed a $2.5 \mathrm{~kg}$ maintenance diet per day. Eleven mature Dorper rams, recording a mean body weight of $69.6 \pm 9.2 \mathrm{~kg}$ and mean age of $18 \pm 4.7$ months, were used in the trial. A group of six rams were trained for semen collection with the aid of the artificial vagina (AV), while in the remaining five rams, semen was collected using the electro ejaculator (EE). Immediately after collection, ejaculates were evaluated macroscopically and microscopically for semen volume, semen colour, semen $\mathrm{pH}$, semen wave motion, sperm motility, sperm cell concentration, sperm viability and morphology. The results of the trial generally showed that semen in Dorper rams may be collected using the AV or EE methods throughout the year. However, an overall significant better semen quality collected by the AV versus the EE collection method was recorded. Generally, semen of significantly higher quality was recorded in summer, autumn and spring (both collection techniques). The tendency in the current trial was that the EE technique of semen collection was the less reliable method. Consequently the AV is recommended as the more acceptable method of semen collection in the Dorper. Winter is not generally recommended for semen collection, especially when using the EE.
\end{abstract}

Keywords: Artificial vagina, electro-ejaculator, season, semen quality

\#Corresponding author: greylijp@ufs.ac.za

\section{Introduction}

Sheep production plays an integral role in South African agriculture. The current study focused on the Dorper breed, because of its internationally renowned carcass quality, adaptability, hardiness, good mothering ability, and high overall demand in certain countries worldwide. The Dorper population represents approximately $28 \%$ of the 22.2 million sheep in South Africa. This breed not only ranks second in terms of sheep numbers in South Africa, but also realises superior prices at sales and auctions (Milne, 2000; Lategan 2012). The easiest and fastest way of disseminating genetic material of this breed may be through cryopreservation of semen and artificial insemination (Al) (Maule, 1962; Ferreira, 2009). For Al to be successfully implemented, viable semen needs to be collected artificially from the male and later deposited in the female, as fresh or after cryopreservation. It is thus essential to determine the semen quality prior to insemination or cryopreservation, and then process only the best-quality semen (Leboeuf et al., 2000). Consequently, the first step in the creation of a cryopreservation semen bank or controlled breeding and an Al programme is the use of an effective method of semen collection (Bourdon, 2000).

Various factors affecting ejaculate volume and semen quality have been reported in studies. These include breed, season of the year, age of the male, nutritional status of the animal, reproductive management, skill of the semen collector, responsiveness of the ram, method and the frequency of semen collection (Theron, 2001; Talebi et al., 2009). Two methods of semen collection can generally be used in the ram. Some technicians prefer the artificial vagina (AV), while others prefer or are compelled to use the electro-ejaculator (EE). Which method is the most reliable technique of semen collection for the Dorper 
breed? When addressing the problem, the element of seasonality is a factor to be considered, as sheep are seasonal breeders and this ultimately affects the semen quality (Hafez \& Hafez, 2000; Senger, 2003). In sheep, a decrease in daylight length is known to increase the rate of spermatogenesis, owing to the production of melatonin, which ultimately stimulates the release of the gonadotrophin-releasing hormones $(\mathrm{GnRH})$ (Leahy et al., 2010; Ridler et al., 2012). Greyling \& Grobbelaar (1983) have reported that little information is available about the seasonal fertility of rams (including the Dorper) throughout the year in South Africa.

The aim of the study was therefore to evaluate the seasonal variation in semen quality in Dorper rams, using different collection techniques, and thus ultimately to identify a preferred season for semen processing and $\mathrm{Al}$ in the male.

\section{Material and Methods}

The project was approved by the University of the Free State's Animal Ethical Committee (Project no: 02/12). The trial was conducted on the campus of the University of the Free State, Bloemfontein, South Africa, which is located at $28.57^{\circ}$ south longitude and $25.89^{\circ}$ east latitude and at an altitude of $1304 \mathrm{~m}$ above sea level. Climatological information (ambient temperature, daylight length and relative humidity data) for the entire trial period was obtained from the Department of Agrometeorology (UFS weather station) and is summarized in Table 1.

Eleven mature Dorper rams, recording a mean body weight of $69.9 \pm 9.2 \mathrm{~kg}$ (range of $57.5 \mathrm{~kg}$ to 83 $\mathrm{kg}$ ) and a mean age of $18 \pm 4.7$ months (range of 14 to 24 months) were housed individually in sheltered pens $(3 \mathrm{~m} \times 1.3 \mathrm{~m})$ and fed a pelleted maintenance diet $(8.5 \mathrm{MJ} \mathrm{ME} / \mathrm{kg})$ plus water ad libitum for a total observation period of 12 months (excluding an adaptation and training period) from January 2012 (summer) to January 2013 (summer). Rams were allocated according to age and weight to the two semen collection methods, with the seasons being stipulated as summer (December, January, February), autumn (March, April, May), winter (June, July, August) and spring (September, October, November). Following the adaptation period (feed, environment and handling) of two weeks, the rams were randomly allocated to the two treatment groups.

Semen ejaculates were collected routinely each week for the entire 12-month period. Most materials for semen collection and evaluation were purchased from Ramsem (Bloemfontein, South Africa). Semen of the Dorper rams in the first treatment group $(n=6)$ was collected with the aid of the artificial vagina after training (Evans \& Maxwell, 1987). Only semen in the collection tube was assessed, as semen on the surface of the AV lining (water jacket portion) usually results in thermal damage to the sperm cells (Mitchell \& Doak, 2004).

Semen of the remaining rams $(n=5)$ was collected with the aid of the EE (second treatment group). These rams were restrained in a lateral position on the floor with the glans penis and urethral process exposed. After lubrication and insertion of the rectal probe into the rectum, an electrical stimulation was applied at 3 to 5 second intervals. The electrical current was gradually increased, until ejaculation was induced (Noakes et al., 2009).

The collected semen was stored at $32{ }^{\circ} \mathrm{C}$ in a water bath, and the evaluation was performed within 10 to 15 minutes of collection (Bester, 2006; Zamiri et al., 2010). Immediately after semen collection, the following parameters were evaluated: semen volume, semen colour, semen $\mathrm{pH}$, semen wave motion, sperm motility, sperm concentration (density), sperm viability (percentage live vs. dead sperm) and sperm morphology (abnormalities). These parameters were assessed as follows:

i) The volume of the ejaculate was recorded directly from the calibrated semen collection tube.

ii) The colour of the ejaculate was evaluated as an indicator of sperm concentration (density) and of the possibility of contamination (Greyling \& Grobbelaar,1983; Evans \& Maxwell, 1987).

iii) The semen $\mathrm{pH}$ was determined with the aid of a digital $\mathrm{pH}$ meter (hand-held $\mathrm{pH} / \mathrm{mV} /$ temperature/RS 232 meter). Care was taken to ensure that the probe was immersed in the semen sample when taking the $\mathrm{pH}$ readings.

iv) Semen wave motion: $10 \mu \mathrm{L}$ semen were drawn up in an automatic pipette and placed on a prewarmed microscope slide $\left(32{ }^{\circ} \mathrm{C}\right)$, and evaluated under a microscope (x10 magnification). This semen wave motion was microscopically scored on a scale of 0 to 5 (Hafez \& Hafez, 2000).

v) The sperm motility was assessed microscopically using a volume of $10 \mu \mathrm{L}$ semen diluted in 990 $\mu \mathrm{L}(1: 100)$ pre-warmed $\left(32^{\circ} \mathrm{C}\right)$ skimmed milk. Thereafter $10 \mu \mathrm{L}$ of this mixture was placed onto a pre-warmed microscope slide and covered with a pre-warmed cover slip $\left(32{ }^{\circ} \mathrm{C}\right)$. Low magnification under a phase contrast microscope was used ( $\times 40$ magnification) for this microscopic evaluation. A total of 100 sperm cells was evaluated for each semen sample, and 
was classified as motile or non-motile sperm and expressed as a percentage (Zamiri et al., 2010).

vi) The sperm concentration of the ejaculate was determined with the aid of an improved Neubauer haemocytometer. Here $10 \mu \mathrm{L}$ semen was diluted in $990 \mu \mathrm{L}(1: 100)$ distilled water, to dilute and kill all sperm (Salisbury et al., 1978; Mitchell \& Doak, 2004).

vii) The sperm viability (\% live vs. dead sperm) and morphology (\% abnormalities) were determined by making a semen eosin-nigrosin stain. Sperm that stained red were presumed dead, while the live sperm remained transparent. The procedure entailed taking $10 \mu \mathrm{L}$ semen and diluting it with $100 \mu \mathrm{L}$ of the eosin-nigrosin stain (1: 10) (Theron, 2001; Mitchell \& Doak, 2004).

The results were statistically analysed using the PROC GLM procedures of SAS (1995). The one-way analysis of variance (ANOVA) for repeated measures was used to compare the two treatments. Parameters were then considered significant at the confidence level of $P<0.05$. Where treatment means differed significantly for a specific trait, Tukey's method for multiple comparisons was used to determine which means ultimately differed significantly (SAS, 1995).

\section{Results}

Training of the semen collection of rams with the aid of the AV technique was performed successfully within a week, with 4 of $6(67 \%)$ rams responding to the AV collection within two days of training. Semen collection started in February 2012 (summer) and ended in January 2013 (summer), thus covering all four seasons of the year (Table 1).

Table1 Mean ambient temperature, relative humidity and daylight length for the observation period

\begin{tabular}{|c|c|c|c|c|c|c|c|c|c|}
\hline \multirow[b]{2}{*}{ Season } & \multicolumn{3}{|c|}{ Ambient temperature $\left({ }^{\circ} \mathrm{C}\right)$} & \multicolumn{3}{|c|}{ Relative humidity (\%) } & \multicolumn{3}{|c|}{ Daylight length (h) } \\
\hline & Min & $\operatorname{Max}$ & Mean & Min & $\operatorname{Max}$ & Mean & Min & Max & Mean \\
\hline Summer & 8.4 & 36.4 & 24.5 & 5.9 & 93.2 & 54.0 & 12.4 & 14.0 & 13.4 \\
\hline Autumn & -1.8 & 32.9 & 17.2 & 8.8 & 92.6 & 47.6 & 10.2 & 12.4 & 11.2 \\
\hline Winter & -3.6 & 29.2 & 10.9 & 7.1 & 94.0 & 47.1 & 10.1 & 11.3 & 10.5 \\
\hline Spring & 1.7 & 34.1 & 18.6 & 5.3 & 90.5 & 36.5 & 11.3 & 13.5 & 12.6 \\
\hline
\end{tabular}

The mean $( \pm \mathrm{SD})$ semen volume, colour and semen $\mathrm{pH}$ collected for the 12-month period with the aid of $A V$ and $E E$ are set out in Table 2. No significant $(P>0.05)$ differences in semen volume were recorded for the AV technique of semen collection. However, with the EE collection of semen, a significant $(P<0.05)$ difference was recorded between seasons. The overall average semen volume for the seasons was similar $(1.1 \mathrm{~mL})$ for both collection techniques. There was a tendency $(P<0.05)$ for the AV group to produce samples with a higher colour score, which is indicative of samples with a high concentration of sperm. There was thus a significant $(P<0.05)$ difference in colour score between the AV and EE semen collection techniques, as well as for the overall mean between treatments for the different seasons. No significant $(P$ $>0.05$ ) difference was recorded (in the semen $\mathrm{pH}$ ) between the AV and EE techniques, (see Table 2).

The mean $( \pm$ SD) seasonal semen wave motion, sperm motility, sperm abnormalities and sperm viability (\% live sperm) obtained using the different techniques of semen collection are presented in Table 3 , while Figure 1 illustrates the sperm cell concentration (semen density) over the observation period.

A significant $(P<0.05)$ difference in overall sperm motility between the two collection techniques was recorded throughout the year, with the AV usually generating semen with a higher sperm motility. When evaluating the seasonal variation regarding sperm motility using the AV collection technique, no significant $(P>0.05)$ difference was recorded between autumn (natural breeding season) and spring (commonly regarded as the supplementary breeding season). Regarding the overall sperm wave motion, a significant $(P$ $<0.05)$ difference was recorded between the two collection techniques, and between seasons. For the sperm abnormalities, no significant $(P>0.05)$ difference was recorded between the two collection techniques for the entire observation period. Seasonally, however, there were distinct $(P<0.05)$ sperm abnormality differences within each technique, with the most abnormalities being recorded in the winter for both collection 
Table 2 Mean ( \pm SD) macroscopic seasonal variation in semen volume, colour and $\mathrm{pH}$, following the use of the artificial vagina and electro-ejaculator semen collection techniques in rams for the entire observation period

\begin{tabular}{|c|c|c|c|}
\hline Semen parameters & Season & Artificial vagina & Electro-ejaculator \\
\hline \multirow[t]{4}{*}{ Semen volume $(\mathrm{mL})$} & Summer & $\mathrm{x}_{1.1} \pm 0.2^{\mathrm{a}}$ & ${ }^{\mathrm{y}} 1.0 \pm 0.4^{\mathrm{b}}$ \\
\hline & Autumn & ${ }^{x} 1.1 \pm 0.3^{a}$ & ${ }^{z} 0.7 \pm 0.4^{b}$ \\
\hline & Winter & ${ }^{\mathrm{x}} 1.1 \pm 0.3^{\mathrm{a}}$ & $\mathrm{x}_{1.2} \pm 0.6^{\mathrm{a}}$ \\
\hline & Spring & ${ }^{x} 1.1 \pm 0.3^{a}$ & ${ }^{x} 1.3 \pm 0.4^{b}$ \\
\hline \multirow[t]{4}{*}{ Semen colour $(0-5)$} & Summer & ${ }^{\mathrm{y}} 3.6 \pm 0.3^{\mathrm{a}}$ & ${ }^{\mathrm{x}} 2.8 \pm 0.7^{\mathrm{b}}$ \\
\hline & Autumn & ${ }^{x} 3.9 \pm 0.4^{a}$ & ${ }^{\mathrm{x}} 2.5 \pm 0.8^{\mathrm{b}}$ \\
\hline & Winter & ${ }^{\mathrm{z}} 2.8 . \pm 0.4^{\mathrm{a}}$ & ${ }^{\mathrm{y}} 1.9 \pm 0.6^{\mathrm{b}}$ \\
\hline & Spring & ${ }^{\mathrm{y}} 3.6 \pm 03^{\mathrm{a}}$ & ${ }^{x} 2.6 \pm 1.0^{b}$ \\
\hline \multirow[t]{4}{*}{ Semen $\mathrm{pH}$} & Summer & ${ }^{\mathrm{x}} 6.8 \pm 0.1^{\mathrm{a}}$ & ${ }^{\mathrm{x}} 6.8 \pm 0.1^{\mathrm{a}}$ \\
\hline & Autumn & ${ }^{\mathrm{x}} 6.8 \pm 0.1^{\mathrm{a}}$ & ${ }^{\mathrm{x}} 6.9 \pm 0.2^{\mathrm{a}}$ \\
\hline & Winter & ${ }^{x} 6.8 \pm 0.3^{a}$ & ${ }^{x} 6.8 \pm 0.3^{a}$ \\
\hline & Spring & ${ }^{x} 6.7 \pm 0.2^{a}$ & ${ }^{x} 6.7 \pm 0.2^{a}$ \\
\hline
\end{tabular}

Table 3 Mean $( \pm$ SD) microscopic seasonal sperm characteristics for the artificial vagina and electroejaculator semen collection techniques in Dorper rams

\begin{tabular}{|c|c|c|c|}
\hline Semen parameters & Season & Artificial vagina & Electro-ejaculator \\
\hline \multirow[t]{4}{*}{ Sperm motility (\%) } & Summer & ${ }^{x} 76.7 \pm 5.3^{a}$ & ${ }^{\mathrm{x}} 68.8 \pm 8.0^{\mathrm{b}}$ \\
\hline & Autumn & ${ }^{x} 76.7 \pm 8.14^{a}$ & ${ }^{x} 65.8 \pm 10.2^{b}$ \\
\hline & Winter & ${ }^{y_{5}} 52.2 \pm 15.3^{a}$ & ${ }^{y} 32.6 \pm 15.8^{b}$ \\
\hline & Spring & ${ }^{x} 77.8 \pm 5.2^{a}$ & ${ }^{\mathrm{x}} 63.3 \pm 18.5^{\mathrm{b}}$ \\
\hline \multirow[t]{4}{*}{ Sperm wave motion (0-5) } & Summer & ${ }^{y_{3}} 3.5 \pm 0.3^{a}$ & ${ }^{\mathrm{x}} 2.8 \pm 0.7^{\mathrm{b}}$ \\
\hline & Autumn & $x_{3.9} \pm 0.3^{a}$ & ${ }^{x} 2.5 \pm 1.0^{b}$ \\
\hline & Winter & ${ }^{\mathrm{z}} 2.7 \pm 0.7^{\mathrm{a}}$ & ${ }^{\mathrm{y}} 1.9 \pm 0.6^{\mathrm{b}}$ \\
\hline & Spring & ${ }^{\mathrm{x}} 3.7 \pm 0.4^{\mathrm{a}}$ & ${ }^{\mathrm{x}} 2.7 \pm 1.7^{\mathrm{b}}$ \\
\hline \multirow[t]{4}{*}{ Sperm abnormalities (\%) } & Summer & ${ }^{\mathrm{y}} 7.1 \pm 2.4^{\mathrm{a}}$ & ${ }^{\mathrm{y}} 6.2 \pm 2.6^{\mathrm{a}}$ \\
\hline & Autumn & ${ }^{z} 5.3 \pm 4.0^{a}$ & ${ }^{\mathrm{z}} 4.2 \pm 3.0^{\mathrm{a}}$ \\
\hline & Winter & ${ }^{x} 9.0 \pm 2.4^{a}$ & ${ }^{\mathrm{x}} 8.5 \pm 2.9^{\mathrm{a}}$ \\
\hline & Spring & ${ }^{\mathrm{z}} 4.4 \pm 1.9^{\mathrm{a}}$ & ${ }^{\mathrm{z}} 4.6 \pm 2.8^{\mathrm{a}}$ \\
\hline \multirow[t]{4}{*}{ Sperm viability (\%) } & Summer & ${ }^{y} 78.5 \pm 4.5^{a}$ & ${ }^{y} 74.3 \pm 6.9^{b}$ \\
\hline & Autumn & ${ }^{\mathrm{x}} 84.2 \pm 9.1^{\mathrm{a}}$ & ${ }^{\mathrm{x}} 82.2 \pm 10.6^{\mathrm{a}}$ \\
\hline & Winter & ${ }^{\mathrm{z}} 48.0 \pm 17.3^{\mathrm{a}}$ & ${ }^{z} 39.0 \pm 14.6^{b}$ \\
\hline & Spring & ${ }^{x} 81.3 \pm 5.3^{a}$ & ${ }^{\mathrm{y}} 72.8 \pm 16.3^{\mathrm{b}}$ \\
\hline
\end{tabular}

techniques. For sperm viability or percentage live sperm (in both collection techniques), there was no significant $(P>0.05)$ difference for semen collected in autumn, while the other seasons recorded a significant $(P<0.05)$ difference, with the AV recording a higher sperm viability. Thus, the winter season generally yielded semen of inferior quality for both the semen collection techniques. 


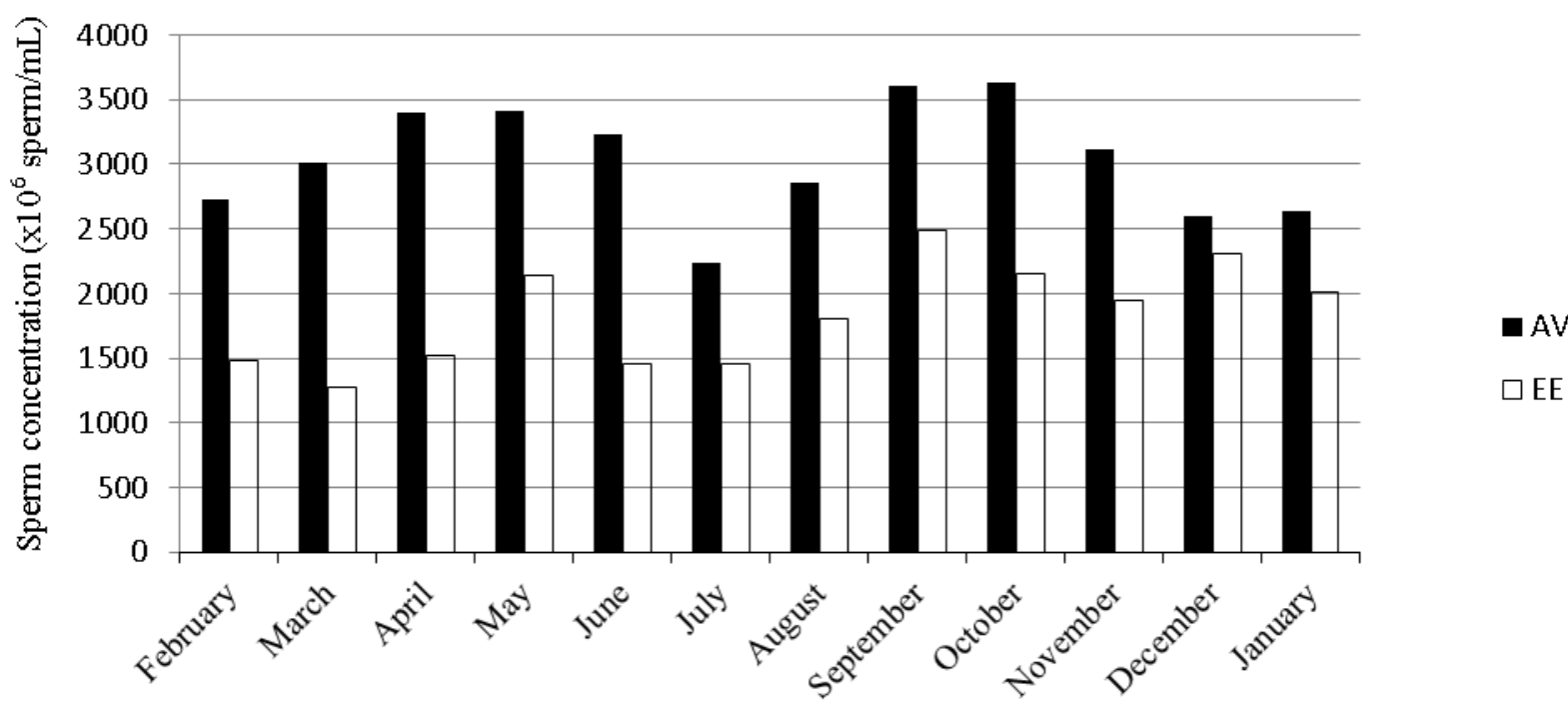

Figure 1 Mean monthly sperm concentration $\left(\times 10^{6} \mathrm{sperm} / \mathrm{mL}\right)$ recorded in Dorper rams, using the artificial vagina (AV) or electro-ejaculator (EE) semen collection techniques for a 12-month period.

\section{Discussion}

The week training timeframe for the ram AV semen collection group was acceptable and in agreement with that quoted by Hafez \& Hafez (2000). All rams were always willing to be collected with the AV (indication of libido) as the AV technique usually simulated the natural mating (ejaculation) process (Greyling \& Grobbelaar, 1983). The rams in the EE semen collection group, however, were not trained for semen collection. Thus, this technique of semen collection was more variable and less repeatable. When using the $\mathrm{AV}$, the ejaculate volume for each season stayed relatively constant throughout the year, as the collection of semen with the AV simulates the natural ejaculation process. Collecting semen using the AV generally required the active participation of the ram, leading to the involvement of the nervous and endocrine systems. Under the influence of these systems, the gonadotrophic hormones (SSH and ICSH) are generally produced in sufficient quantities to regulate the reproductive system (Hafez \& Hafez, 2000).

There was generally a disinclination in the application of the electro-ejaculator for semen collection. During the first four months of treatment, the EE group vocalized, and vocalization normally being associated with pain, said to be caused by EE (Palmer, 2005; Malejane, 2013). In this EE treatment group, even though vocalization stopped in the fifth month of collection, it did not imply that electro-ejaculation was no longer uncomfortable. Possibly the rams had become accustomed to the stress inflicted by electro-ejaculation. It could also imply that the rams had become accustomed to being handled (Ortiz-de- Montellano et al., 2007). Table 2 demonstrates that the semen obtained from the EE treated group generally yielded a thin cream to milk colour $(1.9 \pm 0.6$ to $2.8 \pm 0.7$ ) semen sample, which was less concentrated when compared with the AV group (Evans \& Maxwell, 1987). The semen collected during the winter for the AV collection group and all samples from the EE group recorded a milky to cloudy colour (less dense) throughout the study period. Autumn (natural breeding season) recorded a slight increase in semen colour for the AV semen collection group, which usually indicated a corresponding higher sperm count (concentration) (Greyling \& Grobbelaar, 1988).

The semen $\mathrm{pH}$ (indicator of semen acidity or alkalinity) has been reported for different breeds of rams (Greyling \& Grobbelaar, 1983; Hafez \& Hafez, 2000) as varying between 5.9 and 7.3. The current trial (mean semen pH $6.7 \pm 0.3$ to $6.9 \pm 0.2$ recorded for the AV and EE groups, respectively) fell within these ranges. From this trial, the EE may be assumed not to have caused excessive stimulation of the accessory glands, which would normally result in a more alkaline semen $\mathrm{pH}$ being recorded (Greyling \& Grobbelaar, 1988). The semen $\mathrm{pH}$ in this current trial may imply that the 10 - 15 minute waiting period (to prevent further sperm cell metabolism), is an aspect to be considered and $\mathrm{pH}$ is to be measured immediately. The delay in the processing of the fresh undiluted semen has been reported to possibly induce the semen $\mathrm{pH}$ to become more acidic, due to degradation of fructose by the sperm cells (Hafez \& Hafez, 2000; Zamiri et al., 2010). 
Semen wave motion is usually seen as a superficial indication of the motility and viability of the sperm (Evans \& Maxwell, 1987; O'Hara et al., 2010). Table 3 illustrates a significant difference between the two semen collection techniques, with the AV resulting in a higher semen wave motion. Semen wave motion in both treatment groups was significantly $(P<0.05)$ lower during winter. The AV method of semen collection yielded semen with a wave motion score of $>3$ in summer, autumn and spring, while the EE technique yielded a score of $<3$ in all seasons of the year. In general, semen scoring $>3$ for semen wave motion (on the scale of 0 to 5), is accepted as suitable for Al or cryopreservation (O'Hara et al., 2010). Regarding the semen wave motion in this trial, all the AV samples obtained, except for those collected in winter, should be acceptable for AI, especially cryopreservation, while all samples from the EE group could generally be seen as inferior and to be used selectively. This parameter of wave motion generally ruled out the EE technique as a preferred method for semen collection and demonstrated that ram semen should preferably not be collected in winter (Arrebola et al., 2010; Zamiriet al., 2010).

High sperm motility is regarded by researchers as a good indication of high semen quality, with acceptable fertilizing ability and good fertility (Evans \& Maxwell, 1987). Sperm motility could be used when estimating the number of doses per ejaculate. Sperm motility in both treatment groups was significantly $(P$ $<0.05$ ) lower during the winter (June to August) period in this trial (Table 3). These findings are in agreement with those of Talebi et al. (2009), but contrary to those of Karagiannidis et al. (2000). Ambient temperature has been reported to affect sperm motility. Consequently, the winter temperatures recorded in Bloemfontein, which were low (minimum $-3.6^{\circ} \mathrm{C}$ ), could have played a role in the motility recorded (Table 1 ). Evans \& Maxwell (1987) reported that an ambient temperature of below $10^{\circ} \mathrm{C}$ affected sperm quality negatively. High summer temperatures were generally found to affect sperm motility to a lesser degree (Zamiri et al., 2010).

Zamiri et al. (2010) reported a wide range of percentage live ram sperm in the ejaculates, varying between $60 \%$ and $90 \%$. Fourie et al. (2004) reported mean percentage live sperm values of $74.6 \pm 26 \%$ and $68.5 \pm 3.7 \%$ for extensively and intensively managed Dorper rams, respectively. In the current trial $84.2 \pm$ $9.1 \%$ and $82.2 \pm 10.6 \%$ were recorded for the percentage live sperm in the AV and EE collection groups in autumn (natural breeding season), respectively. These autumn percentage live sperm values showed no significant $(P>0.05)$ difference for both collection techniques. The percentage sperm viability (\% live sperm) for winter in both collection techniques, however, was much lower $(48.0 \pm 17.3 \%$ for the AV and $39.0 \pm$ $14.6 \%$ for the EE). The trial recorded no significant difference in sperm morphology for both the AV and EE methods, in agreement with Greyling \& Grobbelaar (1983) and Matthews et al. (2003). Every semen ejaculate normally contains a small portion of abnormal sperm. The seasonal trend was recorded (Table 3 ) as $\leq 10 \%$ abnormalities, which is similar to that recorded by Karagiannidis et al. (2000). The most common abnormalities recorded throughout the trial were tail-less and coiled tailed sperm, coiled tails being most common in winter. The low percentage of abnormalities recorded, following EE, showed this method was not detrimental to the sperm morphology. Sperm morphology may ultimately be affected by heat stress, transportation, temperature, collection frequency, age, season of the year, disease and nutrition (Hafez \& Hafez, 2000).

The sperm cell concentration or sperm density is usually an indication of the number of sperm cells per unit volume $(\mathrm{mL})$ of seminal plasma. Figure 1 shows that the semen collected by the AV method recorded a significantly $(P<0.05)$ higher sperm concentration than the EE method of collection, throughout the year (all samples) in the Dorper. These findings are in agreement with previous findings, as the EE tends to induce an excessive production of seminal fluid, thus diluting the overall sperm concentration in the ejaculate (Evans \& Maxwell, 1987). The highest sperm concentration was recorded during April and May (autumn) and September and October (spring), for the AV group something to be kept in mind when collecting and processing semen of the Dorper (Matthews et al., 2003).

\section{Conclusions}

Results from the trial show that both the $\mathrm{AV}$ and electro-ejaculation collection methods were able to yield semen from Dorper rams throughout the year. However, the AV collection method generally yielded significantly better quality semen than the EE method of collection. Researchers are encouraged to learn how to utilize the EE efficiently, as circumstances could evolve that warrant or necessitate its use. In general, semen of significantly $(P<0.05)$ higher quality in the Dorper was recorded in summer, autumn and spring. This trial thus recommends that semen should be collected only during these seasons. The Dorper breed showed little seasonality in terms of spermatogenesis. The low seasonality recorded in this breed could differ in exotic sheep breeds. Winter was recorded as a limiting factor to semen quality in the Dorper.

\section{Acknowledgements}

The authors wish to thank Botswana College of Agriculture and the University of the Free State, for financial support. 


\section{References}

Arrebola, F., Pérez-Marín, C.C. \& Santiago-Moreno, J., 2010. Limitation of seasonality in reproductive parameters of Mediterranean bucks, using photoperiod treatment. Small Rumin. Res. 89, 31-35.

Bester, N., 2006. Effect of different dietary energy level on productive and reproductive traits in Dorper rams. M.Sc. dissertation, University of the Free State, Bloemfontein, South Africa.

Bourdon, R.M., 2000. Understanding Animal Breeding. ( $2^{\text {nd }}$ ed). Prentice-Hall, USA.

Evans, G. \& Maxwell, W.M.C., 1987. Salamon's Artificial Insemination of Sheep and Goats. Butterworths. Sydney, Australia.

Ferreira, P., 2009. Bonsmara Born to Breed - Born to Lead. ABC Press, Cape Town, South Africa.

Fourie, P.J., Schwalbach, L.M., Neser, F.W.C. \& Greyling, J.P.C., 2005. Relationship between body measurements and serum testosterone levels of Dorper rams. Small Rumin. Res. 56, 75-80.

Greyling, J.P.C. \& Grobbelaar, J.A.N., 1983. Seasonal variation in semen quality of Boer and Angora goat rams using different collection techniques. S. Afr. J. Anim. Sci. 13, 250-252.

Greyling, J.P.C. \& Grobbelaar, J.A.N., 1988. Artificial insemination in sheep. Farming in South Africa Mutton sheep, Brochure 7, Department of Agriculture, South Africa.

Hafez, E.S.E. \& Hafez, B., 2000. Reproduction in Farm Animals. ( $7^{\text {th }}$ ed.). Lippincott Williams \& Wilkins, USA.

Karagianndis, A., Varsakili, S., Alexopoulos, C. \& Amarantidis, I., 2000. Seasonal variation in semen characteristics of Chios and Friesian rams in Greece. Small Rumin. Res. 37, 125-130.

Lategan, D., 2012. Dorpers into the new century (brochure and training manual). Charmaine Alberts, Brandfort, South Africa.

Leahy, T., Marti, J.I., Evans, G. \& Maxwell, W.M.C., 2010. Seasonal variation in the protective effect of seminal plasma on frozen-thawed ram spermatozoa. Anim. Reprod. Sci. 119, 147-153.

Leboeuf, B., Restall, B. \& Salamon, S., 2000. Production and storage of goat semen for artificial insemination. Anim. Reprod. Sci. 6, 113-141.

Malejane, C.M., 2013. Seasonal variation in semen quality of Dorper rams using different collection techniques. M.Sc. dissertation, University of the Free State, Bloemfontein, South Africa.

Matthews, N., Bester, N. \& Schwalbach, L.M.J., 2003. A comparison of ram semen collected by artificial vagina and electro-ejaculation. S. Afr. J. Anim. Sci. 33, 28-30.

Maule, J.P., 1962. The Semen of Animals and Artificial Insemination. Commonwealth Agricultural Bureaux, England.

Milne, C., 2000. The history of the Dorper sheep. Small Rumin. Res. 36, 99-102.

Mitchell, J.R. \& Doak, G.A., 2004. The artificial insemination and embryo transfer of dairy and beef cattle (Including information pertaining to goats, sheep, horses, swine and other animals). (9 $9^{\text {th }}$ ed.). Pearson Education, Inc., Upper Saddle River, New Jersey.

Noakes, D.E., Parkinson, T.J. \& England, G.C.W., 2009. Veterinary Reproduction and Obstetrics. Saunders, China.

O’Hara, L., Hanrahan, J.P., Richardson, L., Donovan, A., Fair, S., Evans, A.C.O. \& Lonergan, P., 2010. Effect of storage duration, storage temperature, and diluents on the viability and fertility of fresh ram sperm. Theriogenology 73, 541-549.

Ortiz-de-Montellano, M., Galindo-Maldonado, F., Cavazos-Arizpe, E.O., Aguayo-Arceo, A.M., Torres-Acosta, J.F.J. \& Orihuela, A., 2007. Effect of electro-ejaculation on the serum cortisol response of Criollo goats (Capra hircus). Small Rumin. Res. 69, 228-231.

Palmer, C.W., 2005. Welfare aspects of theriogenology: Investigating alternatives to electro ejaculation of bulls. Theriogenology $64,469-479$.

Ridler, A.L., Smith, S.L. \& West, D.M., 2012. Ram and buck management. Anim. Reprod. Sci. 130, 180-183.

Salisbury, G.W., Van Demark, N.L. \& Lodge, I.R., 1978. Physiology of Reproduction and Artificial Insemination of Cattle, $\left(2^{\text {nd }}\right.$ ed.). Freeman, USA.

SAS, 1995. Statistical Analysis System user's guide ( $6^{\text {th }}$ ed.). SAS Institute Inc., North Carolina, USA.

Senger, P.L., 2003. Pathways to pregnancy and parturition. Cadmus Professional Communication, USA.

Talebi, J., Souri, M., Moghaddam, A., Karimi, I. \& Mirmahmoodi, M., 2009. Characteristics and seasonal variation in the semen of Markhoz bucks in western Iran. Small Rumin. Res. 85, 18-22.

Theron, O., 2001. The effect of season and nutrition on the reproductive potential and sexual characteristics of Boer goat bucks. M.Sc. dissertation, University of the Free State, Bloemfontein, South Africa.

Zamiri, M.J., Khalili, B., Jafaroghli, M. \& Farshad, A., 2010. Seasonal variation in seminal parameters, testicular size, and plasma testosterone concentration in Iranian Moghani rams. Small Rumin. Res. 94, 132-136. 